\title{
Ripple analyze and design considerations for an interleaved boost converter (IBC) for a PV source
}

\author{
R. Buerger, A. Péres, R. Hausmann, R. A. Reiter and A. L. Stankiewicz \\ University of Blumenau (FURB) \\ Rua São Paulo, 3250 \\ 89030-000, Blumenau, SC - Brazil \\ Phone:+55 47 32216022, e-mail: roberto_buerger@hotmail.com, aperes.furb@gmail.com
}

\begin{abstract}
This paper approaches the interleaved boost converter (IBC) for photovoltaic systems (PVS) with efficiency control. The purpose of this converter is to transfer the low DC PV voltage to a high DC voltage at its output. The low output voltage ripple and especially the low input current ripple (for MPPT) are analyzed, verified and compared to $\mathrm{N}$ cell IBCs. To improve the efficiency of the IBC, the control decides how many commutation cells are used, in relation to the actual power. This paper also shows to determine the critical PV current needed to work in continuous conduction mode. Finally, a dual IBC is experimental tested to verify the theoretically approaches.
\end{abstract}

\section{Key words}

Critical Inductance, Interleaved Boost Converter, Improved Efficiency, Photovoltaic System, Ripple Analyze.

\section{Introduction}

The worldwide endeavor of states to supply their population and industry with renewable energy (RE) had a big compact to the renewable energy sources like wind craft, photovoltaic (PV) and Fuel Cell (FC). These RE sources don't emit pollution, and can be used as a decentralized supply system. The electric energy of these sources can't be injected directly in the national energy grid, so it is necessary to process and appropriate that voltages and currents.

In the case of the PV panel, the output is a DC voltage with current source characteristics [1]. When the PV system is used local and not injecting energy to the grid, a voltage controlled converter is charging a link of batteries. For grid connected sources a frequency converter has to be added in series. The converter has to control the Maximum Power Point (MPP). In many cases the duty cycle is adjusted like the Maximum Power Point Tracker (MPPT). Almost every MPPT technique requires a low input current and voltage ripple to work appropriately. The literature shows that an interleaved technique is a good way to reduce the current ripple coming from the PV system [2]. The merits of the use of interleaved technology is not only the lower input current ripple, but also a lower output voltage ripple, which can be used to reduce the DC link capacitors [2].

Many works have focused the interleaved boost converter (IBC) in relation of current and voltage ripple, efficiency analyzing, simplification of small signal model, coupling and decoupling inductances [2], [3].

This paper is focused in the analysis of the current and voltage ripple, control of efficiency and application on a PV system of $1890 \mathrm{Wp}$.

Fig. 1 shows the proposed IBC with four commutation cells. In this work the DC link voltage is not controlled, so it varies with the duty cycle in relation to the MPPT.

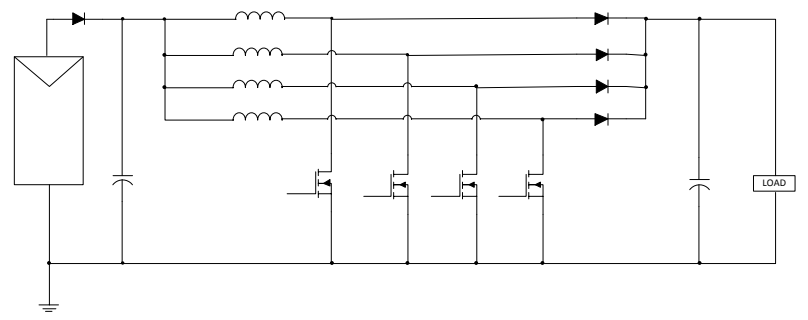

Fig. 1. Four cell IBC.

\section{Analysis of the input current and output voltage ripple}

\section{A. Analysis of the Input Current}

The IBC's voltage and current waveforms are similar to the conventional boost converter. The difference lay in the input current and output voltage ripple. Because of the $\mathrm{N}$ times commutation cells in parallel, the input current and output current work with a frequency $\mathrm{N}$ times the switching frequency, where $\mathrm{N}$ is the number of cells in parallel. The DC link is equal to the conventional boost converter, but distinguishes in the value.

The following analysis is made for Continuous Conduction Mode (CCM) and all components are considered ideal, e.g. have no losses, with no ESR.

The analysis depends on the duty cycle. In general the quantity of parts depends on the commutation cells are 
used. So exist $\mathrm{N}$ operations parts with its limits in $\mathrm{D}$ with $1 / N$ (for example in the four cell IBC $\Delta D=0.25$ ).

The commands to the switches are $360^{\circ} / \boldsymbol{N}$ degrees shifted.

Before the analysis of the input current, it's helpfully to assume some relations. The duty cycle of the input current is defined as $d=\frac{t_{r}}{\tau}$ and the relation between $d$ and $D$ depends on its operation part. In the first part ( $D=0 \ldots 0.25) d$ is equal to $N \cdot D$. The off-time of the switch can be rewritten as $d_{\text {off }}=1-d$. These relations are illustrated in Figure 2. In this figure are shown the duty cycles of the IBC each cell, their respectively current and the definition of $d$ for the four conditions of $D$. Thus the $\mathrm{N}$ switches share the input current according to their operation part. For the four cell IBC during the first operation part, $\mathrm{D}=0 \ldots 0.25$, there is no overlapping current in the switches. For the second operation part, D $0.251 \ldots 0.5$, two switches share at the same time the input current, and respectively for the other two operation parts, three or four switches will share the input current. The time when the switches begin to share the input current occurs in the same time of the duty cycle of the operation part is arrived, and ends at a theoretically duty cycle equal 1.

During the ON state of switch, the rising slope is expressed as follows in (1).

$$
\frac{\Delta i_{L}}{\Delta t}=\frac{V_{p v}}{L}
$$

The OFF state has as consequence the falling slope of the inductor current, how is shown in (2).

$$
\frac{\Delta i_{L}}{\Delta t}=\frac{V_{p v}-V_{d c}}{L}=\frac{-D \cdot V_{p v}}{L \cdot D_{o f f}}
$$

A raise of $\mathrm{D}$ causes a decrease of the PV voltage, so the static gain of the boost is to be valid.

$$
\frac{V_{d c}}{V_{p v}}=\frac{1}{D_{o f f}}
$$

The PV source is considered as a current source. So the change of the duty cycle has theoretically no effect on the modulus of the input current. Like this, the input current ripple is calculated similarly as with constant output voltage [1]. With this information it is possible to deduce the input current ripple. The input current is the sum of $i_{L 1}, i_{L 2}, i_{L 3}$ and $i_{L 4}$. So the input current ripple calculation is made using (4).

$$
\Delta i_{p v}=\Delta i_{L 1}+\Delta i_{L 2}+\Delta i_{L 3}+\Delta i_{L 4}
$$

The value of the input current ripple is divided in four parts, and depends on the duty cycle. The first part is from $0<D<0.25$, the second part from $0.251<D<0.5$ and so on. To get the ripple in relation to the duty cycle are used equations (1), (2), (3) and (4).
The equations (5), (6), (7) and (8) are used to make the input current ripple calculation for each part of operation, depending on the duty cycle condition.

To transform (5)-(8) into equations with variable input voltage it is necessary to use (3).

A general equation for input current ripple calculation is given by (9), where $N_{o n}$ is the quantity of switches in on state during the $\tau$ period.

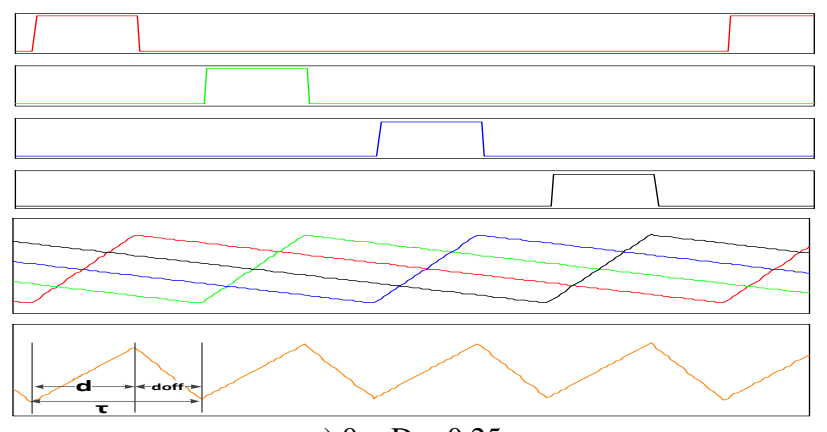

a) $0<\mathrm{D}<0.25$

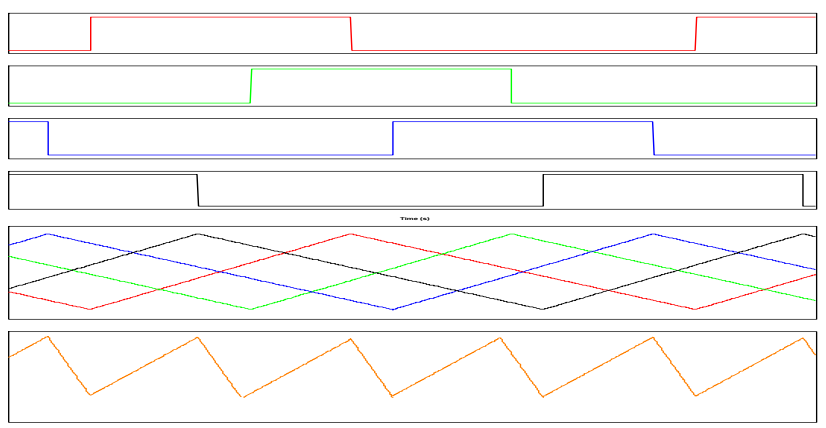

b) $0.251<\mathrm{D}<0.5$

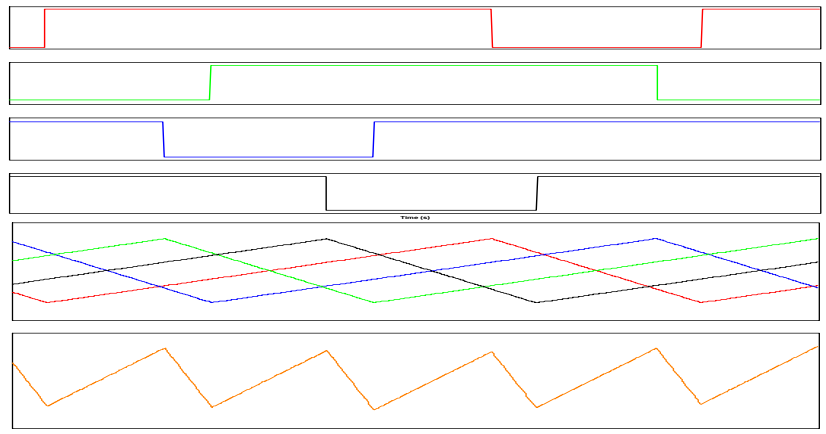

c) $0.51<\mathrm{D}<0.75$

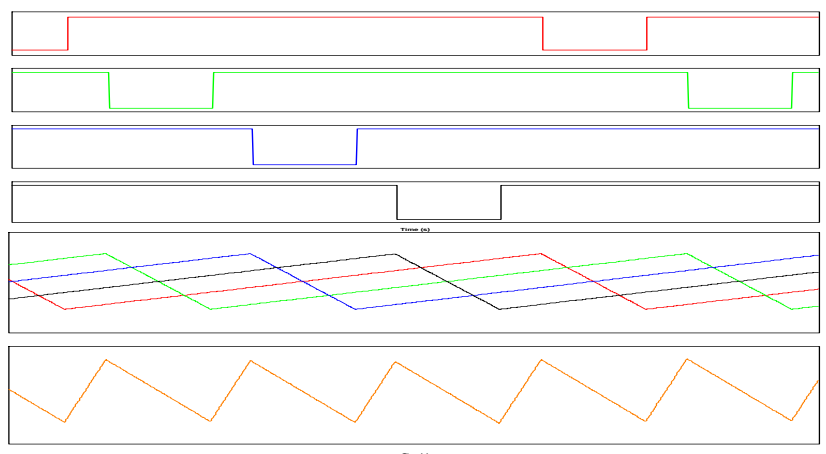

d) $0.751<\mathrm{D}<1$

Fig. 2. Variation of the duty cycle.

$\Delta I_{i n}=\frac{V_{p v}}{L} T\left(\frac{1-4 D}{1-D}\right) D \quad 0<D<0.25$ 


$$
\begin{aligned}
& \Delta I_{i n}=\frac{V_{p v}}{L} T\left(\frac{2-4 D}{1-D}\right)(D-0.25) \quad 0.251<D<0.5 \\
& \Delta I_{i n}=\frac{V_{p v}}{L} T\left(\frac{3-4 D}{1-D}\right)(D-0.5) \quad 0.51<D<0.75 \\
& \Delta I_{i n}=\frac{V_{p v}}{L} T(4 D-3) \\
& \Delta I_{i n}=\frac{V_{d c}}{L}\left(N_{o n}-N D\right) \frac{T}{N} d
\end{aligned}
$$

With these equations it is possible to obtain a relation between input current ripple and duty cycle, like shown in Fig. 3. In this figure the red line represents the ripple of a boost converter with only one switch; the green line represents an IBC with two switches; the blue line represents an IBC with three switches and the yellow line represents an IBC with four switches. It can be seen that using an IBC with two switches the input current ripple reduces to the half value of using only one switch. In the same manner, using a four switches IBC the input current ripple will be reduced for a quarter in comparison to the only one switch boost converter.

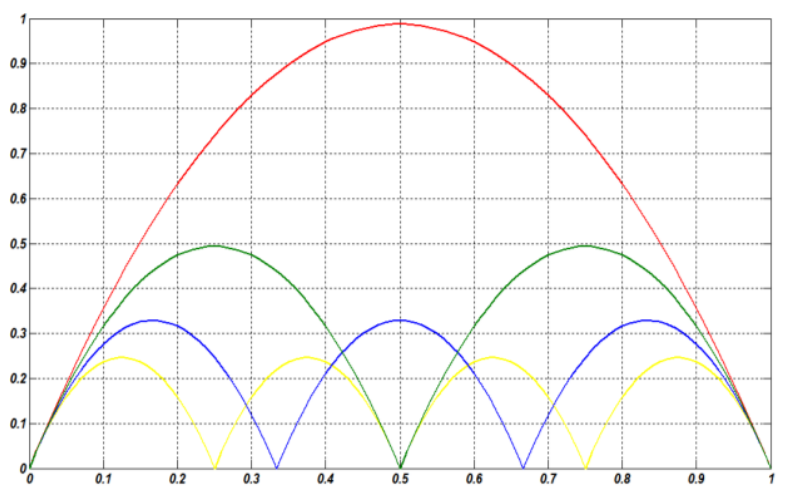

Fig. 3. Input current ripple in relation to the duty cycle for one, two, three and four switches boost converter

\section{B. Analyze of the output voltage ripple}

The lifetime of an electrolytic capacitor is related to the current ripple over itself. So an objective of this work is to minimize the capacitor current ripple. The IBC has minimized also the capacitor current. Similarly to the input current the output current of the inductances, is the sum of the inductance currents. The capacitor current can be calculated with (10).

$$
I_{C o}=I_{L o}-I_{o}
$$

It is evident that the average charge of the capacitor is the same as the conventional boost converter, see Figure 4. But the ripple is smaller and so the lifetime of the capacitor could be raised.

The value of the capacitance $(C)$ depends on the variation of the capacitor voltage $\left(\Delta V_{o}\right)$ and the charge variation $(\Delta Q)$. The capacitor charge variation $(\Delta Q)$ is obtained calculating the triangular area above the output current waveform shown by the blue line of the

Fig. 4. The output current is considered constant with no ripple in a switching period.

$$
C=\frac{\Delta Q}{\Delta v_{o}}
$$

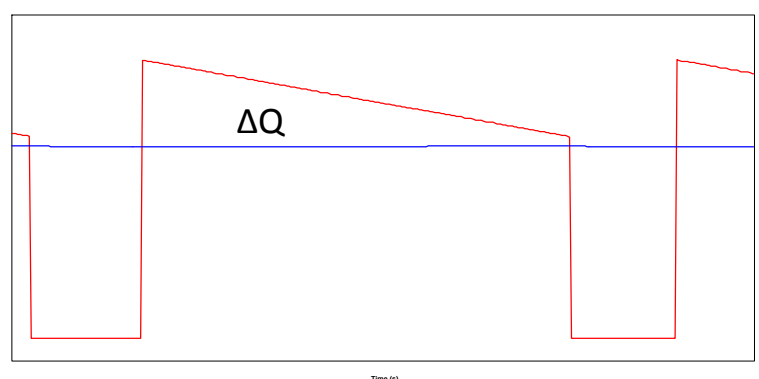

Fig. 4. Capacitor current (red line) and output current (blue line) waveforms.

Depending on the duty cycle part, in general during the time $d_{o f f} \tau$, the maximum number of inductances that are conducting their energies to the output, the minimum ripple will be obtained. The average inductor current is given by (12) and (13) expresses the area above $I_{o}$.

$$
\begin{aligned}
& I_{L}=\frac{V_{o}}{R D_{\text {off }} N} \\
& \Delta Q=\left\{\left(N_{\text {off }} \cdot I_{L}\right)+\frac{V_{o}}{R}\right\} \cdot \frac{T}{N} d_{\text {off }}
\end{aligned}
$$

$N_{\text {off }}$ is the number of currents connected to the capacitors during $d_{\text {off }}$.

The relative output voltage ripple can be expressed as in (14). Figure 5 shows the relative output voltage in relation to duty cycle and the number of cells used in an IBC.

$$
\Delta v_{o}=\frac{\Delta Q}{C}=\frac{T V_{o} d d_{o f f}}{R C N^{2} D_{o f f}}
$$

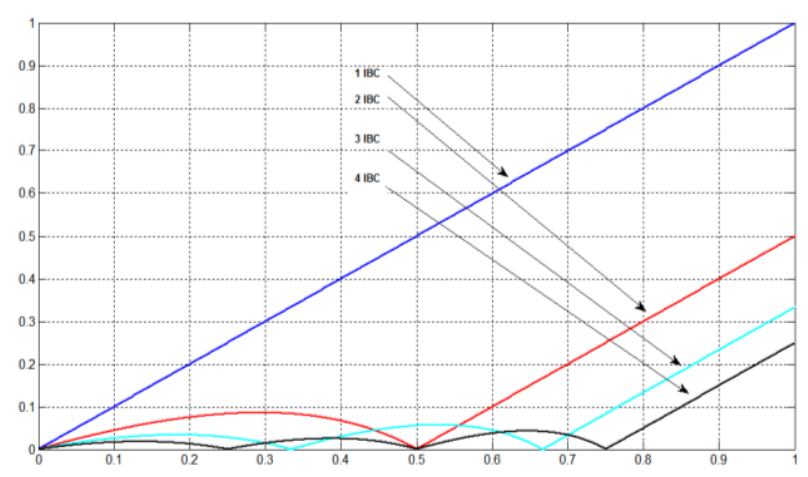

Fig. 5. Relative output voltage in relation to duty cycle for 1,2 , 3 and 4 cells in an IBC.

\section{Design of the dual IBC and its control}

\section{A. CCM Critical Current}

Because this paper presents a dual IBC in CCM, it is necessary to define the worst irradiation and temperature condition. The inductance current cannot be zero in the CCM. Equation (15) shows the minimal current, for the worst condition. 


$$
I_{L \min }=I_{L}-\frac{\Delta I_{L}}{2}
$$

In the critical mode $I_{L \text { min }}$ becomes zero.

$$
I_{L \min }=O=\frac{I_{p v}}{2}-\frac{\Delta I_{L}}{2}
$$

In the dual IBC the inductance current is half the input current from the PV source. Because the PV can be considered as a current source, the highest ripple over the inductance, with constant output voltage and constant input current, occurs when the duty cycle is at its highest value.

From (16) it already can be seen that $\Delta I_{L}=I_{\text {pvcrit }}$ for the dual IBC.

$$
\Delta I_{L}=\frac{V_{o} \cdot I_{o} \cdot D T}{L \cdot I_{p v}}
$$

Insert equation (17) into (16) it is possible to calculate the minimal PV current $I_{p v}$ for a given $D$ to secure CCM. The duty cycle depends on the temperature for a constant output voltage and constant input current.

$$
I_{p v c r i t}=\frac{V_{o} \cdot D_{o f f} \cdot D T}{L}
$$

In general form it can be used (19) to calculate the critical current (irradiance) or critical inductance needed to work in CCM.

$$
I_{p v c r i t}=\frac{V_{o} \cdot D_{o f f} \cdot D T \cdot N}{2 L}
$$

To raise the efficiency in lower power condition, the control of the converter will switch off one or several commutation cells on lower powers. In this case it is possible to work with lower irradiance condition, because the inductance current will not have to share the PV current. For this objective it is necessary to determine the actual possible power from the PV source. For this objective there will be two current sensors (LTSR-15NP) to measure the inductance currents. Another benefit of the current sensors is to equilibrate the inductance currents.

\section{B. Design of the proposed converter}

Following the analysis presented in Section 2, a 1900W dual IBC with appropriate control was chosen to verify the considerations in this paper.

The source is presented by $14 \mathrm{PV}$ modules connected in series, which ends with STC in $247.8 \mathrm{~V}$ and $7.67 \mathrm{~A}$ at its output. The MPPT works based on a temperature control algorithm.

In Figure 6 it can be seen the whole system to verify the theoretical considerations in this work. It is a first prototype and it was mounted as a modular system to facilitate transportation and modifications in the hardware.

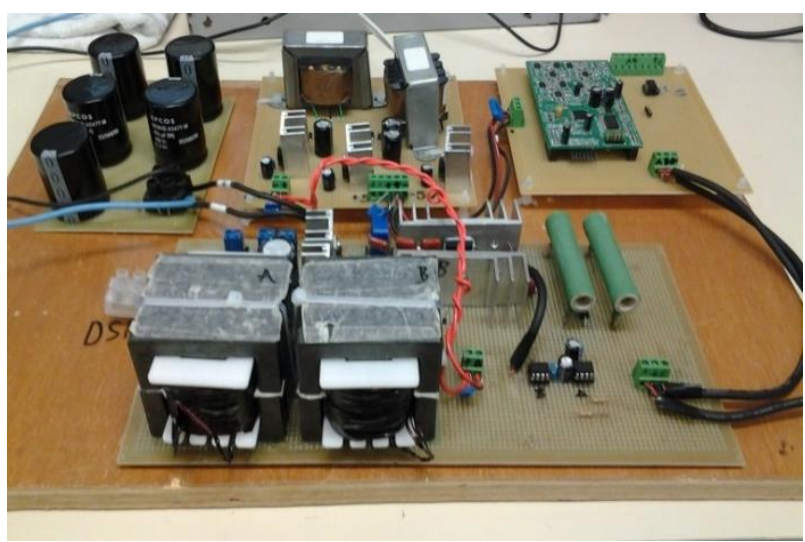

Fig. 6. Proposed dual IBC system.

With a $25^{\circ} \mathrm{C}$ temperature, an output capacitor link of $C=2.35 \mathrm{mF}$, two inductances $L_{1}=L_{2}=4.2 \mathrm{mH}$ and MPP voltage at $V_{p v}=247.8 \mathrm{~V}$, the PV array is capable to supply $1900 \mathrm{Wp}$. The commutation frequency of the switches $\left(f_{s}\right)$ was chosen as $35 \mathrm{kHz}$.

\section{Experimental results}

The following experimental results verify in parts the theoretically developed conclusions.

Figure 7 to Figure 9 are with a duty cycle $\mathrm{D}=0.3$ and an input power of $1820 \mathrm{~W}$. Figure 10 and Figure 11 are taken with a duty cycle $\mathrm{D}=0.66$ and finally the Figures 13 and 14 was taken with $\mathrm{D}=0.3$.

Figure 7 shows the signal switch commands and the inductor currents, it can be seen the displacement between the signals and currents respectively and that in this condition no overlapping occur $(D=0.3)$.

Figure 8 shows the input and output currents and voltages. This figure shows the efficiency of the dual IBC: input and output voltages and currents with very small ripple. In Fig. 8 signal 1 represents the output current (dark blue), signal 2 represents the input voltage (light blue), signal 3 represents the input current (magenta) and signal 4 represents the output voltage (green).

Figure 9 presents the output current before and after the link capacitor, showing the effectiveness of the filtering.

Figure 10 shows the signal switch commands and the inductor currents for $\mathrm{D}=0.66$, showing that an overlapping occurs in this condition.

Figure 11 presents the output current before and after the link capacitor for $\mathrm{D}=0.66$.

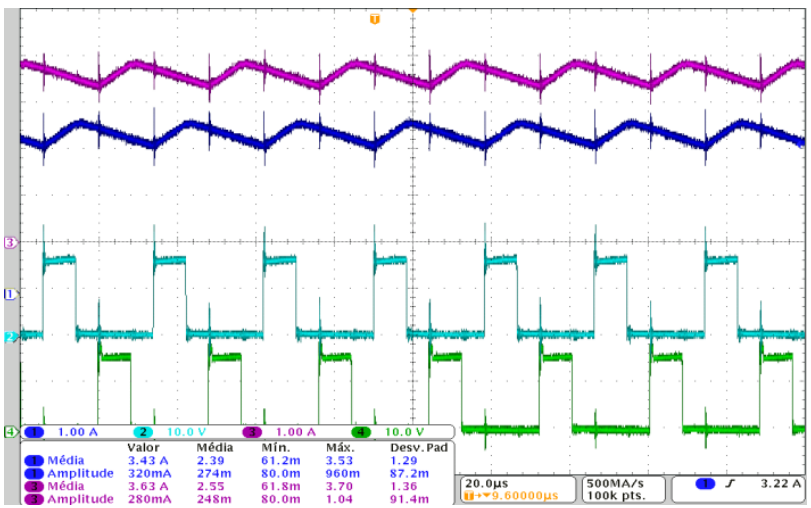

Fig. 7. Switch commands and inductor currents for $\mathrm{D}=0.3$. 


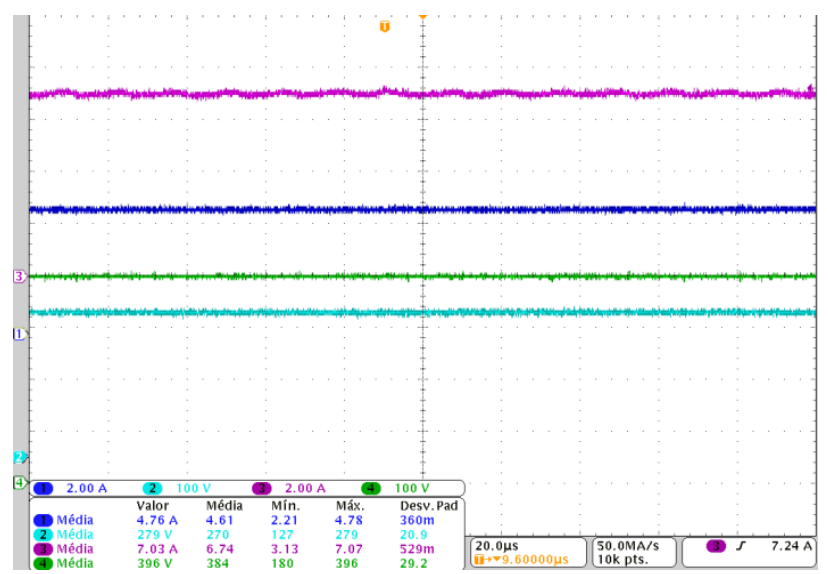

Fig. 8. Input and output currents and voltages for $\mathrm{D}=0.3$.

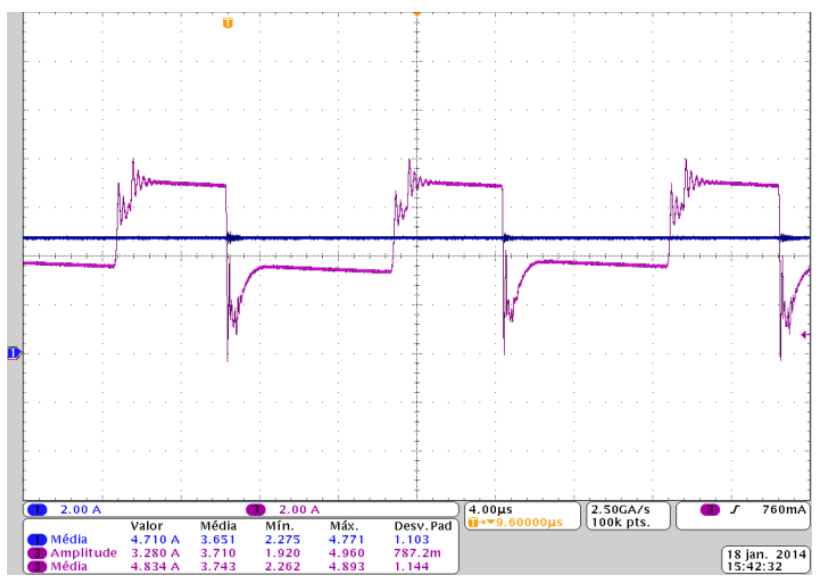

Fig. 9. Output current Io before (magenta) and after (dark blue) the link capacitor $(\mathrm{D}=0.3)$.

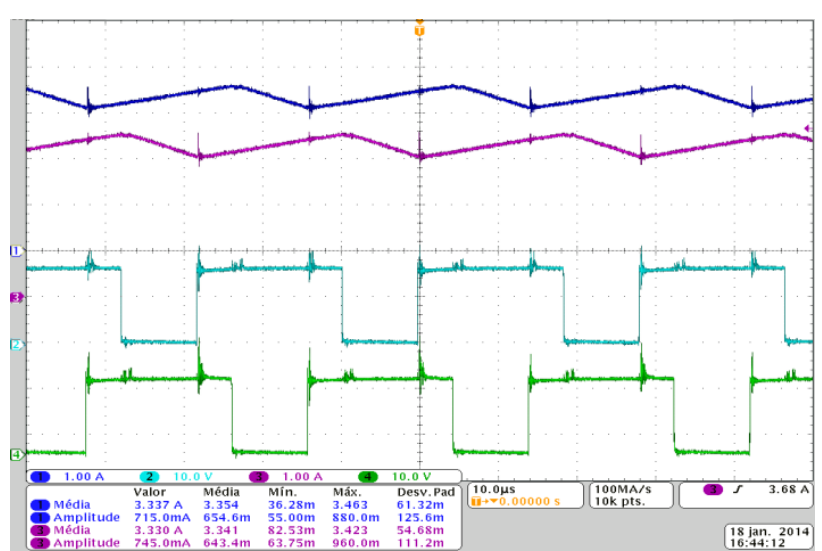

Fig. 6. Inductance currents and gate commands for $\mathrm{D}=0.66$.

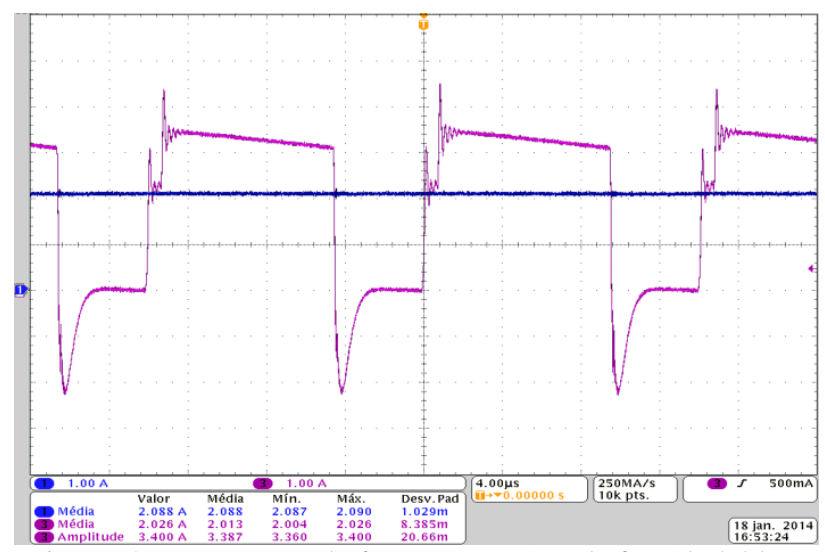

Fig. 7. Output currents before (magenta) and after (dark blue) the capacitor $(\mathrm{D}=0.66)$.
Figures 12 and 13 show the input and output currents and voltages and input power waveforms for the IBC operating with one and two active switches respectively. The input current benefits from the use of two active switches and the ripple is remarkable lower.

The efficiency obtained for one switch operation was $94.4 \%$ and for two switches was $95.0 \%$ using the same level of power $(\cong 700 \mathrm{~W})$. These results demonstrate that independent of the number of switches the efficiency is the same and it is not necessary to shut down any MOSFET when the IBC is in lower power operation.

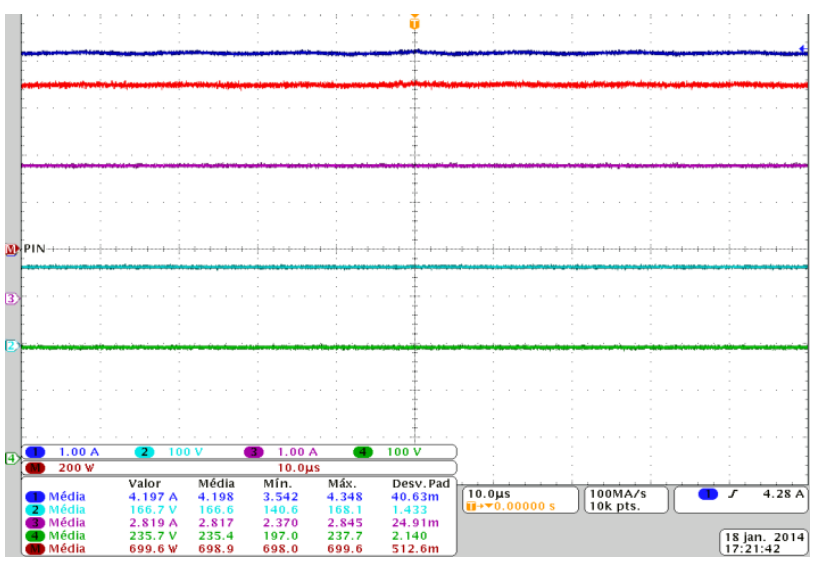

Fig. 82. Input and output currents and voltages and output power using two active switches.

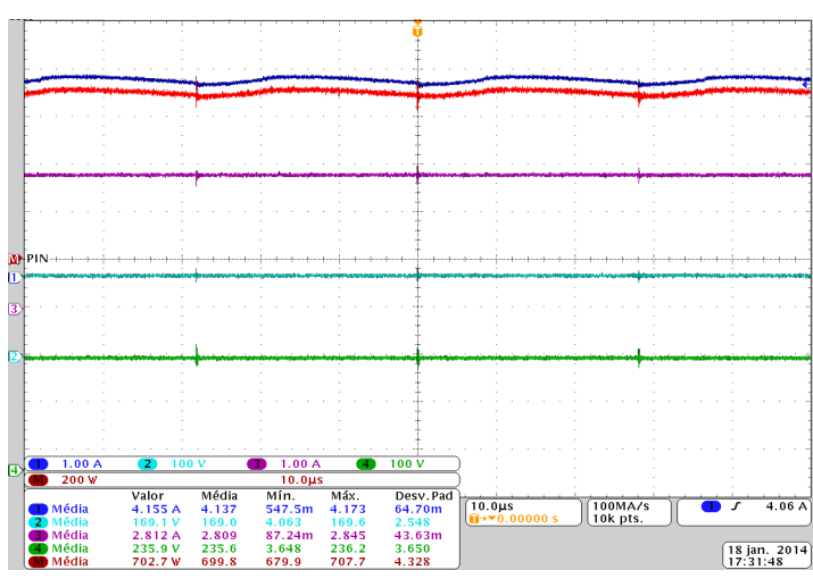

Fig. 9 Input and output currents and voltages and output power using only one active switch.

\section{Conclusion}

Some tests of the dual IBC verify the fact that the overlapping of the inductance currents depend on the operation part. During a duty cycle of $\mathrm{D}=0.3$ there is no overlapping and during $\mathrm{D}=0.66$ the current overlaps at the end and begin of a turn-on cycle. The effectiveness of the converter for one or two active switches is not differenced sufficient to be remarked in this paper. The experimental results show that the current are shared between the two cells used in this work. The input current variation and the output voltage variation diminish with the increase of cell number used for the IBC. 


\section{Acknowledgement}

The authors gratefully acknowledge financial support from CAPES-Brazil, the National Council for the Improvement of Higher Education.

\section{References}

[1] N. Mohan, T. M. Undeland, W. P. Robbins, Power electronics converter, application and design, 3rd ed. JOHN WILEY \& SONS INC., 2003, pp.78-82.

[2] G. Y. Choe, J. S. Kim, H. S. Kang and B. K. Lee, "An Optimal Design Methodology of an Interleaved Boost Converter for Fuel Cell Applications", Journal of Electrical
Engineering \& Technology, 2010, Vol. 5, No. 2, pp. 319 328.

[3] L. Y. Chang, K. H. Chao, T. C. Chang, "Application of High Voltage Ratio and Low Ripple Interleaved DC-DC Converter for a Fuel Cell", WSEAS TRANSACTIONS on CIRCUITS and SYSTEMS, January 2013, Issue 1, Volume 12, pp. 26-35.

[4] H. B. Shin, J. G. Park, S. K. Chung, H. W. Lee and T. A. Lipo, "Generalised steady-state analysis of multiphase interleaved boost converter with coupled inductors", in Proc. of IEE Electr. Power Appl., May 2005, Vol. 152, No. 3, pp.584-594.

[5] S. Y. Tseng and C. T. Tsai, "Photovoltaic Power System with an Interleaving Boost Converter for Battery Charger Applications", Intern. Journal of Photoenergy, 2012, Article ID 936843,15 pages. 